\title{
A new species of Tereancistrum (Monogenea, Dactylogyridae) from the gills of three Leporinus species (Characiformes, Anostomidae) and a revised description of Tereancistrum parvus
}

\author{
ALINE C. ZAGO, FÁBIO H. YAMADA, LIDIANE FRANCESCHINI, MARCELA F. \\ BONGIOVANI, PRISCILLA O.F. YAMADA and REINALDO J. DA SILVA \\ Universidade Estadual Paulista/Unesp, Instituto de Biociências, Câmpus de Botucatu, \\ Rua Professor Doutor Antônio Celso Wagner Zanin, 250, 18618-689 Botucatu, SP, Brazil \\ Manuscript received on September 27, 2016; accepted for publication on January 11, 2017
}

\begin{abstract}
The present study describes Tereancistrum flabellum n. sp. (Dactylogyridae, Ancyrocephalinae) from the gills of the anostomid fishes Leporinus friderici, Leporinus amblyrhynchus and Leporinus elongatus from two freshwater ecosystems in the south east of Brazil. This new species is mainly characterized by the morphology of the copulatory complex (such as the MCO base formed by two fan-shaped structures, and accessory piece flattened, curved, rigid and channeled), a dorsal anchor with a well-developed superficial and inconspicuous deep root, and the shape of the accessory anchor sclerite with small spathulate termination. Tereancistrum flabellum n. sp. is the first record of a dactylogyrid from L. amblyrhynchus. The description of Tereancistrum parvus is also emended to correct and complement previous descriptions and the species is reported for the first time in Schizodon nasutus.
\end{abstract}

Key words: Ancyrocephalinae, anostomid fish, gill ectoparasites, monogeneans, Neotropical region.

\section{INTRODUCTION}

The Anostomidae Günther, 1864 family includes fish species that are widely distributed from southern Central America to tropical and subtemperate regions of South America (Nelson 2006). Many anostomid species are recognized by their habit of feeding in an inclined position, and constitute a significant part of the fish biomass in different aquatic habitats (Garavello and Britski 2003).

Correspondence to: Aline Cristina Zago

E-mail: alinecristhina@yahoo.com.br
Leporinus Agassiz, 1829 is the most diverse genus among anostomids, with 87 species, while the Schizodon Agassiz, 1829 genus is represented by 14 species (Nelson 2006). Some larger members of Leporinus and Schizodon are known for their spawn migrations in the Paraná-Paraguay river system and in the Amazon and Orinoco basins. Because of their annual migrations, these species are subjected to significant exploitation by commercial and subsistence fisheries as an important food source for the people of South America (Garavello and Britski 2003). 
Although monogeneans are common fish parasites, despite the efforts of taxonomists their diversity in the Neotropics remains largely unknown (Cohen et al. 2013). Dactylogyridae Bychowsky, 1933 is the most abundant taxon in South America, and included in this family is Tereancistrum Kritsky, Thatcher and Kayton, 1980, which accommodates parasites of characiform fishes in the Neotropical region (Thatcher 2006).

Currently, eight species have been included in this genus, seven of which have been described in Brazil: Tereancistrum kerri Kritsky, Thatcher and Kayton, 1980 (type species) from Brycon melanopterus (Cope, 1872) collected in the Januaca Lake, Amazonas state, Brazil; Tereancistrum ornatus Kritsky, Thatcher and Kayton, 1980 from Prochilodus reticulatus Valenciennes, 1850 from Rio Cauca, Juanchito, Cali and Valle, Colombia; Tereancistrum parvus Kritsky, Thatcher and Kayton, 1980 from Leporinus fasciatus (Bloch, 1794) collected in the Amazon River Basin (Kritsky et al. 1980); Tereancistrum toksonum Lizama, Takemoto and Pavanelli, 2004 and Tereancistrum curimba Lizama, Takemoto and Pavanelli, 2004 from Prochilodus lineatus (Valenciennes, 1847) from the Upper Paraná River floodplain, Brazil (Lizama et al. 2004); Tereancistrum arcuatus Cohen, Kohn and Boeger, 2012 from Salminus brasiliensis (Cuvier, 1816) from the Paraná River, Brazil (Cohen et al. 2012); Tereancistrum pirassununguensis Cepeda, Ceccarelli and Luque, 2012 from P. lineatus from the Mogi Guaçu River, in the south east of Brazil (Cepeda et al. 2012); and Tereancistrum paranaensis Karling, Lopes, Takemoto and Pavanelli, 2014 from Schizodon borellii (Boulenger, 1900) from the Upper Paraná River floodplain, Brazil (Karling et al. 2014).

During an investigation of helminth fauna of fish from the Sapucaí-Mirim River and Jurumirim Reservoir in the south east of Brazil, specimens of an undescribed species of Tereancistrum were recovered from the gills of Leporinus friderici
(Bloch, 1974), Leporinus amblyrhynchus Garavello and Britski, 1987 and Leporinus elongatus Valenciennes, 1850.

The present study describes this new species and compares it with closely related species of the genus. We also present new data on the morphology of $T$. parvus and report its occurrence in S. nasutus for the first time.

The ZooBank Life Science Identifier (LSID) of this publication is: urn:1sid:zoobank. org:p ub:0 5557665 - 9 F C 4 - 4237 - 8 C 8 B $982278 \mathrm{EF} 1948$.

\section{MATERIALS AND METHODS}

Twenty-four specimens of L. amblyrhynchus, 22 of L. elongatus, 40 of L. friderici, and 40 of S. nasutus were collected from the Sapucaí-Mirim River, São Paulo state, Brazil (20²6'12.5”'S, 4753'18.59”W) between March 2012 and July 2013, while 116 specimens of $L$. friderici were captured from the Jurumirim Reservoir, São Paulo state, Brazil (2312'17' S, 49¹3'19'”W) between April 2011 and July 2012.

The fishes were collected using a nylon monofilament gillnet between 5:00 PM and 7:00 AM, totaling 14 hours of exposure. The capture of fish specimens from the Sapucaí-Mirim River was authorized under a Permanent License for the Collection of Zoological Material (SISBio 13794-1), while collection from the Jurimirim Reservoir was authorized by the Department of the Development of Fishery and Inspection/DEFOP (License \#SP/538/88). All animal procedures were performed in full compliance with the Ethics Committee for Animal Experimentation (protocol \#120) of the Universidade Estadual Paulista (São Paulo State University - UNESP). The fish specimens collected were individually stored in plastic bags and placed in a Styrofoam box with ice for immediate transportation to the laboratory. 
The gills were removed and placed in vials containing hot water with a temperature of around $60^{\circ} \mathrm{C}$. After that, they were shaken, and absolute ethanol was added (Thatcher 2006). The monogeneans were collected and stored in 70\% ethanol solution. Samples of these parasites were stained with Gömöri's trichrome and mounted in Canada balsam for analysis of internal organs. Some specimens were mounted in Hoyer's and Gray and Wess medium for the study of sclerotized structures (Kritsky et al. 1986).

Morphological and morphometric analysis of parasites was carried out using a computerized system for image analysis with differential interference contrast (DIC) - LAS V3 (Leica Application Suite V3; Leica Microsystems, Wetzlar, Germany). The illustrations of the sclerotized structures were performed with the aid of a camera lucida mounted on a Leica DMLS microscope with phase contrast optics. All measurements were presented in micrometers $(\mu \mathrm{m})$ and expressed as means, followed by the range and number of specimens measured (n) in parentheses. The prevalence and mean intensity of infestation was calculated in accordance with Bush et al. (1997).

Voucher host fish specimens were deposited in the fish collection of the Laboratório de Biologia e Genética de Peixes (Fish Biology and Genetics Laboratory) (LBP), Universidade Estadual Paulista (São Paulo State University - UNESP), in the municipality of Botucatu, São Paulo state, Brazil (L. amblyrhynchus - LBP 18811, L. friderici - LBP 18812, S. nasutus - LBP 18825). A holotype and the paratypes of the new species proposed was deposited in the Coleção Helmintológica do Instituto Oswaldo Cruz (Helminthological Collection of the Oswaldo Cruz Institute) (CHIOC), Rio de Janeiro state, Brazil, and the voucher specimens was deposited in the zoological collection of the Instituto Nacional de Pesquisas da Amazônia (Amazonas National Research Institute) (INPA), Amazonas state, Brazil, and the Coleção Helmintológica do Instituto de
Biociências (the Helminthological Collection of the Institute of Biosciences) (CHIBB), of the Universidade Estadual Paulista (São Paulo State University - UNESP), in the municipality of Botucatu, São Paulo state, Brazil.

\section{RESULTS}

\section{MORPHOLOGICAL DESCRIPTION}

Dactylogyridae Bychowsky, 1933

Tereancistrum Kritsty, Thatcher and Kayton, 1980

\section{Tereancistrum flabellum n. sp.}

Diagnosis: Based on 13 specimens. Body elongate, 336 (260-434; n=13) long; greatest width 91 (64-124; $n=13)$ near mid-length; tegument thin and smooth. Cephalic region with two bilateral incipient cephalic lobes; head organs welldeveloped, cephalic glands indistinct. One pair of eyes; accessory granules sometimes present in the cephalic region and trunk. Pharynx spherical, $21(17-26 ; n=11)$ in diameter; esophagus short, bifurcating into two intestinal caeca; caeca confluent posterior to gonads. Haptor $60(52-76 ; n=13)$ long, 100 (84-118; $n=13)$ wide. Ventral anchor 45 (41-49; n=13) long, 16 (15-18; n=13) wide, with well-developed superficial, inconspicuous deep root, evenly curved shaft, point. Accessory anchor sclerite 44 (41-46; $n=13)$ long, 5 (4-5; $n=13)$ wide, with small spathulate termination. Two haptoral muscles attached to accessory sclerites. Dorsal anchor 29 (23-31; $\mathrm{n}=13)$ long, 8 (6-18; $\mathrm{n}=13)$ wide, with well-developed superficial, inconspicuous deep root, evenly curved shaft, point. Ventral bar, 56 (56; n=6) long, $7(6-7 ; n=6)$ wide, with anteromedian indentation, slightly expanded ends. Dorsal bar 34 (33-35; n=13) long, 2 (2-3; n=13) wide, evenly curved with slightly expanded ends. Seven pairs of hooks, 20 (18-21; n=13) long, similar in size, shape, ancyrocephaline distribution (Mizelle 1936); each with robust thumb, recurved point, inflated proximal portion of shank, filamentous hook loop approximately $1 / 2$ shank length. Gonads 


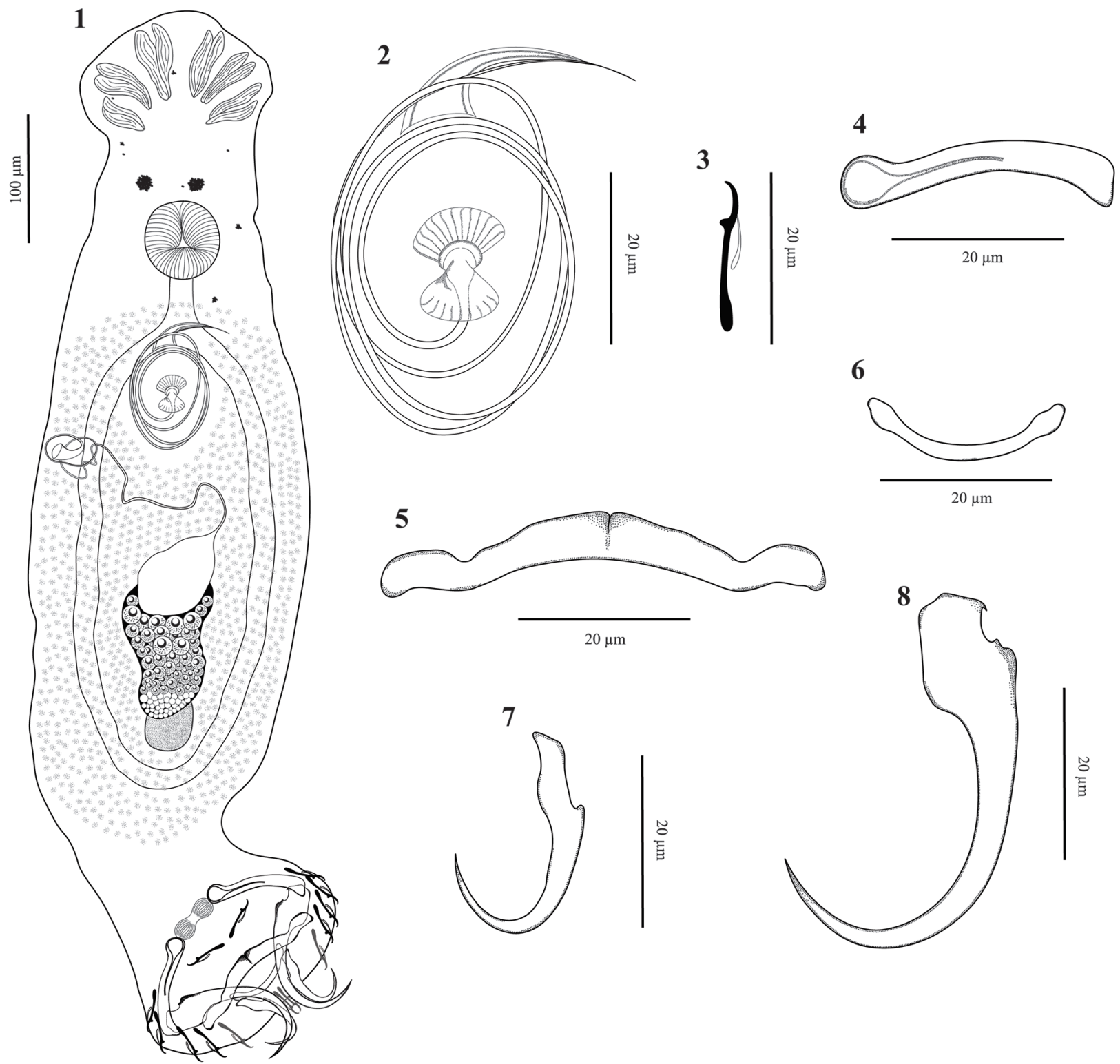

Figures 1-8: Tereancistrum flabellum n. sp. 1. Holotype (ventral view). 2. Copulatory complex (ventral view). 3. Hook. 4. Accessory anchor sclerite. 5. Ventral bar. 6. Dorsal bar. 7. Dorsal anchor. 8. Ventral anchor.

intercaecal, slightly overlapping. Ovary elongate, $32(25-39 ; n=2)$ long, with greatest width $40(20$ $61 ; \mathrm{n}=2)$ at anterior end. Testis $22(\mathrm{n}=1)$ long, 16 $(n=1)$ wide. Male copulatory organ (MCO), a coiled tube of 3.5 clockwise rings; ring diameter 28 (2038; $\mathrm{n}=13$ ); MCO base formed by two fan-shaped structures. Accessory piece flattened, curved, rigid, channeled, distal portion guarding termination of
MCO. Accessory piece not articulate with $\mathrm{MCO}$, $15(12-18 ; n=9)$ long, greatest width $2(2-3 ; n=9)$. Vagina dextral, comprising an elongate, sclerotized, fine tube; vagina aperture bugle-shaped. Seminal receptacle ovate. Vitellaria coextensive with intestinal caeca, absent near reproductive organs. Oviduct, ootype, uterus, seminal vesicle, prostatic reservoir and eggs not observed. 


\section{TAXONOMIC SUMMARY}

ZooBank Life Science Identifier (LSID): urn:1sid:zoobank.org:act:AEFD7EEA-4E024BD5-83DD-8B14D3126920.

Type host: Leporinus friderici (Bloch, 1794) (Characiformes: Anostomidae).

Other hosts: Leporinus amblyrhynchus Garavello and Britski, 1987 and Leporinus elongatus Valenciennes, 1850 (see measurements in Table I).

Site of infection: Gill filaments.

Type locality and collection date: SapucaíMirim River, Grande River Basin, (20²9'38.38'S, 47 51'33.11'W), during the period from March 2012 to July 2013; and Jurumirim Reservoir, Upper Paranapanema River (2312'17'S; 49¹3'19”'W), São Paulo state, Brazil, between April 2011 and July 2012.

Prevalence and mean intensity of infestation: Sapucaí-Mirim River: L. amblyrhynchus - 6 of 24 fish examined (25\%), $2.5 \pm 0.3$ (2-4), respectively; L. elongatus -7 of 22 fish examined (31.8\%), 2.9 \pm 0.6 (1-5), respectively; L. friderici -22 of 40 fish examined (55\%), 3.1 $\pm 0.6(1-12)$, respectively; Jurumirim Reservoir: L. friderici - 18 of 116 fish examined (15.5\%), $1.5 \pm 0.3(1-4)$, respectively.

Specimens deposited: Holotype CHIOC (38460); Paratypes CHIOC (38461, 38462), vouchers INPA $(690,691)$ and CHIBB $(208 \mathrm{~L}$, 209L, 212L, 213L).

Etymology: The specific name is derived from the Latin (flabellum = fan), and refers to the shape of the cirrus base.

\section{REMARKS}

Based on the presence of ventral anchors with accessory anchor sclerite articulated to the tip of the superficial root, one pair of eyespots, overlapping gonads, and due to having a typically ancyrocephaline hook distribution (Mizelle 1936), the new species proposed in this study is considered to be a member of the Tereancistrum genus (Kritsky et al. 1980). The new species can be distinguished from most of its congeners by the morphology of its copulatory organ ( $\mathrm{MCO}$ and accessory piece), which mainly has a fan-shaped cirrus base. The new species resembles $T$. paranaensis in the shape of its ventral and dorsal anchors, but can be differentiated by the number and direction of its MCO rings (3.5 clockwise rings in T. flabellum n. sp.; 1.5 to 2.5 counterclockwise rings in $T$. paranaensis), the shape of its accessory piece, and the dorsal (with antero-median indentation and slightly expanded ends in T. flabellum n. sp. and rectangular in $T$. paranaensis) and ventral bars (evenly curved with slightly expanded ends in T. flabellum n. sp. and rectangular in $T$. paranaensis).

Tereancistrum ornatus and T. curimba are morphologically closed to T. flabellum n. sp. in relation to the accessory anchor sclerite, but differs in the dorsal bar (evenly curved with slightly expanded ends in T. flabellum n. sp.; and Y-shaped in T. ornatus and T. curimba), the number and direction of its $\mathrm{MCO}$ rings (3.5 clockwise rings in T. flabellum n. sp.; $1 \frac{1 / 4}{4}$ counterclockwise rings in T. ornatus and T. curimba), the shape of accessory piece, and the dorsal anchor (with well-developed superficial, inconspicuous deep root, evenly curved shaft, point in T. flabellum n. sp.; and widely divergent roots of anchor base, short shaft and straight point in T. ornatus and T. curimba).

Tereancistrum parvus differs from the new species in relation to the direction of its $\mathrm{MCO}$ rings (clockwise in T. flabellum n. sp.; counterclockwise in $T$. parvus), dorsal bar (evenly curved with slightly expanded ends in T. flabellum n. sp.; and V-shaped in T. parvus), and dorsal anchor (welldeveloped superficial, inconspicuous deep root, evenly curved shaft, point in T. flabellum n. sp.; and slightly curved shaft, short point in T. parvus).

Tereancistrum toksonum can be differentiated from the new species by the number and direction of its $\mathrm{MCO}$ rings (3.5 clockwise rings in $T$. 
TABLE I

Measurements of Tereancistrum flabellum n. sp. in other hosts (Leporinus amblyrhynchus and Leporinus elongatus) from the Sapucaí-Mirim River, south east of Brazil.

\begin{tabular}{|c|c|c|}
\hline Measurements & Leporinus amblyrhynchus $(\mathrm{n}=4)$ & Leporinus elongatus $(\mathrm{n}=5)$ \\
\hline \multicolumn{3}{|l|}{ Body } \\
\hline Length & $460(367-553)$ & $365(271-459)$ \\
\hline Greatest width & $83(48-119)$ & $70(39-91)$ \\
\hline Pharynx (diameter) & 18 & $22(17-27)$ \\
\hline \multicolumn{3}{|l|}{ Haptor } \\
\hline Length & $46(42-49)$ & $44(35-53)$ \\
\hline Width & $89(82-96)$ & $81(76-90)$ \\
\hline \multicolumn{3}{|l|}{ Ventral anchor } \\
\hline Length & $44(43-46)$ & $42(40-45)$ \\
\hline Width & 14 & $14(14-15)$ \\
\hline \multicolumn{3}{|l|}{ Dorsal anchor } \\
\hline Length & $26(25-27)$ & $26(25-27)$ \\
\hline Width & 6 & $7(6-11)$ \\
\hline \multicolumn{3}{|l|}{ Accessory anchor sclerite } \\
\hline Length & $36(35-37)$ & $36(34-38)$ \\
\hline Width & 4 & 4 \\
\hline \multicolumn{3}{|l|}{ Ventral bar } \\
\hline Length & $55(53-58)$ & $55(54-56)$ \\
\hline Width & 6 & $6(5-6)$ \\
\hline \multicolumn{3}{|l|}{ Dorsal bar } \\
\hline Length & $31(30-31)$ & $27(26-28)$ \\
\hline Width & 2 & $2(2-3)$ \\
\hline Hook (length) & $19(18-19)$ & $19(18-20)$ \\
\hline \multicolumn{3}{|l|}{ Ovary } \\
\hline Length & 30 & 40 \\
\hline Greatest width & 13 & 26 \\
\hline \multicolumn{3}{|l|}{ Testis } \\
\hline Length & 27 & 20 \\
\hline Greatest width & 15 & 10 \\
\hline \multicolumn{3}{|l|}{ MCO } \\
\hline Ring diameter & 26 & $22(19-24)$ \\
\hline Accessory piece (length) & $23(22-24)$ & $22(18-26)$ \\
\hline Accessory piece (greatest width) & 4 & $3(2-4)$ \\
\hline
\end{tabular}

"Measurements are in micrometer $(\mu \mathrm{m})$, and the mean is followed by the range.

flabellum n. sp.; $1 \frac{1 / 4}{4}$ counterclockwise rings in $T$. toksonum), the shape of accessory anchor sclerite, ventral (with antero-median indentation, slightly expanded ends in T. flabellum n. sp.; and formed by thin sclerotized membrane with thick posterior margin in T. toksonum) and dorsal bar (evenly curved with slightly expanded ends in T. flabellum n. sp.; and Y-shaped in T. toksonum), and dorsal 
anchor (well-developed superficial, inconspicuous deep root, evenly curved shaft, point in T. flabellum n. sp.; and with long divergent roots, short shaft and straight point in T. toksonum).

Tereancistrum arcuatus differs from the new species by the MCO (a coiled tube of 3.5 clockwise rings in T. flabellum n. sp.; and a strongly arcuate sclerotized tube in T. arcuatus), the shape of accessory anchor sclerite (with small spathulate termination in T. flabellum n. sp.; and with longitudinal groove in T. arcuatus), and dorsal anchor (well-developed superficial, inconspicuous deep root, evenly curved shaft, point in T. flabellum n. sp.; and with robust base, poorly differentiated roots and long straight shaft in T. arcuatus).

Tereancistrum pirassununguensis can be differentiated from the new species in relation to the numbers and direction of its $\mathrm{MCO}$ rings (3.5 clockwise rings in T. flabellum n. sp.; and 2 counterclockwise rings in T. pirassununguensis), the shape of accessory anchor sclerite (with small spathulate termination in T. flabellum n. sp.; and with a little groove at the end in T. pirassununguensis), ventral (with antero-median indentation, slightly expanded ends in T. flabellum n. sp.; and curved in T. pirassununguensis) and dorsal bar (evenly curved with slightly expanded ends in T. flabellum n. sp.; and Y-shaped in T. pirassununguensis), and ventral (with well-developed superficial, inconspicuous deep root, evenly curved shaft, point in T. flabellum n. sp.; and with not developed roots, elongate and evenly curved shaft and point in T. pirassununguensis) and dorsal anchors (welldeveloped superficial, inconspicuous deep root, evenly curved shaft, point in T. flabellum n. sp.; and with well-developed roots, straight shaft and curved point in T. pirassununguensis).

REDESCRIPTION

Tereancistrum parvus Kritsky, Thatcher and Kayton, 1980
Emended diagnosis: Based on 13 specimens. Body elongate, fusiform, 490 (406-558; n=10) long; greatest width 93 (49-125; $n=10)$ near midlength; tegument thin and smooth. Cephalic region with apical and two bilateral incipient lobes; head organs well-developed, cephalic glands indistinct. One pair of eyes; accessory granules sometimes present in the cephalic region and trunk. Pharynx spherical, $33(25-41 ; n=10)$ in diameter; esophagus short, 31 (15-43; n=6) long, $8(3-12 ; n=6)$ wide, bifurcating into two intestinal caeca; caeca not sinuous and confluent posterior to gonads. Haptor subhexagonal, $106(90-126 ; n=11)$ long, 160 (126-179; $\mathrm{n}=11)$ wide. Ventral anchor 65 (55-72; $\mathrm{n}=11)$ long, $20(17-21 ; \mathrm{n}=11)$ wide, with a welldeveloped superficial and inconspicuous deep root. Accessory anchor sclerite $87(70-96 ; n=11)$ long, $8(7-11 ; n=11)$ wide, with broadly spathulate termination. Two haptoral muscles attached to accessory sclerites. Dorsal anchor 56 (42-64; $\mathrm{n}=11)$ long, $18(15-19 ; \mathrm{n}=11)$ wide, slightly curved shaft, short point. Ventral bar, $102(93-108 ; n=11)$ long, and $14(11-16 ; n=11)$ median width, with medial enlargement and tapered ends. Dorsal bar V-shaped, 145 (121-158; n=11) long, 8 (7-10; $\mathrm{n}=11)$ median width, and $94(75-121 ; \mathrm{n}=11)$ distance between the ends of the bar. Seven pairs of hooks, 28 (25-31; $\mathrm{n}=11)$ long, similar in size, shape, ancyrocephaline distribution (Mizelle 1936). Gonads intercaecal, overlapping. Ovary elongated, 63 (34-100; $n=4)$ long, with greatest width 25 (15$31 ; n=4)$ at posterior end. Testis dorsal to ovary, 34 (28-44; n=4) long, $16(5-29 ; n=4)$ wide. Male copulatory organ (MCO), a coiled tube of 3.5 counterclockwise rings; ring diameter 11 (10-13; $\mathrm{n}=11)$. Accessory piece not articulate with cirrus, $36(30-40 ; n=11)$ long, $5(3-10 ; n=11)$ greatest width, with terminal blunt projection. Vagina sinistral, comprising an elongated, sclerotized fine tube. Elliptical seminal receptacle. Seminal vesicle pyriform; small prostatic reservoir lying posterior to the base of the MCO. Oviduct, ootype, 


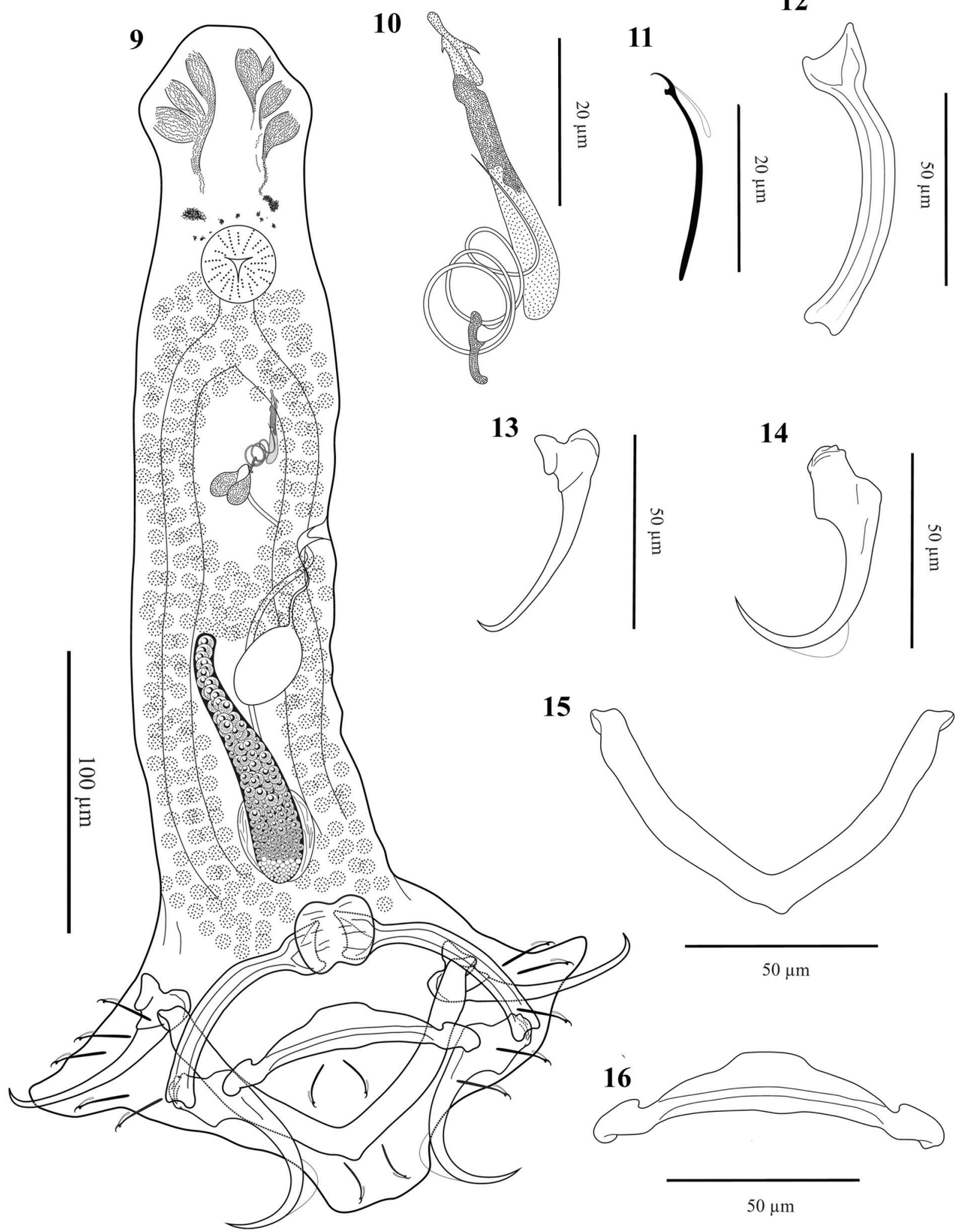

Figures 9-16: Tereancistrum parvus. 9. In toto (ventral view); 10. Copulatory complex (ventral view). 11. Hook. 12. Accessory anchor sclerite. 13. Dorsal anchor. 14. Ventral anchor. 15. Dorsal bar. 16. Ventral bar. 
uterus, and eggs not observed. Vitelline follicles coextensive with intestinal cecum and absent near reproductive organs.

\section{TAXONOMIC SUMMARY}

Type host and locality: Leporinus fasciatus (Bloch, 1794) (Characiformes: Anostomidae) from Steinhart Aquarium, San Francisco, USA (Kritsky et al. 1980).

Hosts, locality and collection date (present study): Schizodon nasutus Kner, 1858 (Characiformes: Anostomidae), Leporinus friderici (Bloch, 1794) (Characiformes: Anostomidae), and Leporinus elongatus Valenciennes, 1850 (Characiformes: Anostomidae) from SapucaíMirim River, Grande River Basin, São Paulo state, Brazil (20²9'38.38”S, 4751'33.11’W), during the period from March 2012 to July 2013.

Site of infection: Gill filaments.

Prevalence and mean intensity of infection: $S$. nasutus - 25 of 40 fish examined (62.5\%), $2.7 \pm$ 0.3 (1-6), respectively; L. friderici -5 of 40 fish examined (12.5\%), $2.2 \pm 0.7$ (1-5), respectively. $L$. elongatus - 4 from 22 fish examined $(10 \%), 1.5 \pm$ 0.5 (1-3), respectively.

Specimens deposited: Vouchers CHIOC (38458, 38459), INPA (692, 693) and CHIBB (210L, 211L).

Specimens examined: voucher specimens deposited by Karling et al. (2014) (CHIOC 37863, 37864, 37865) and Wendt et al. (2015) (CHIOC 38087, 38088).

\section{REMARKS}

Tereancistrum parvus was originally described parasitizing specimens of $L$. fasciatus from the Steinhart Aquarium, San Francisco, USA, by Kritsky et al. (1980). This description was based on a single specimen and presents sclerotized structures of the haptor and MCO only. Two redescriptions of T. parvus were recently proposed and added new data on the morphology of internal organs such as the position of the vagina, testis, ovary, seminal vesicle and the egg morphology (Karling et al. 2014, Wendt et al. 2015). However, some morphological differences were observed in relation to these previous descriptions and they are presented herein to correct and complement the diagnosis of T. parvus. Firstly, the morphology of the MCO is different mainly in terms of the shape of the accessory piece, which consists of a rigid piece, slightly wider at the posterior region and narrower in the anterior region, where it ends in a small projection (Figure 10, present study). The plates of the accessory piece is not clear in the description by Karling et al. (2014) [see Figure 4g in Karling et al. (2014)], and it was represented by Wendt et al. (2015) as a tube with an opening along its lateral extent [see Figure $2 \mathrm{~b}$ in Wendt et al. (2015)]. Furthermore, while Wendt et al. (2015) stated that the terminal projection of the accessory piece described in the original description by Kritsky et al. (1980) was absent, this characteristic was observed in the present study. In addition, the morphology of the vaginal aperture in the present study is different to that described by Wendt et al. (2015) [see Figure 2d in Wendt et al. (2015)], and is more closely related to that represented by Karling et al. 2014 [see Figure 3 in Karling et al. (2014)]. Wendt et al. (2015) stated that the ventral bar is $\mathrm{V}$-shaped, but in fact it is the dorsal bar that has this shape, as described by Kritsky et al. (1980) and confirmed by Karling et al. (2014). In summary, some morphological differences observed in $T$. parvus may also be linked to intraspecific variation according to the fish host species.

\section{DISCUSSION}

Among the nine species of Tereancistrum described to date (including the new species described in the present study), only three were found parasitizing anostomid fishes, such as T. parvus, which were 
reported in L. fasciatus (Kritsky et al. 1980), Leporinus lacustris (Amaral Campos, 1945), Leporinus obtusidens Valenciennes, 1847 (Guidelli et al. 2011), S. borellii (Karling et al. 2014), and L. friderici, L. elongatus, and S. nasutus (present study); T. paranaensis in $S$. borellii (Karling et al. 2014), L. obtusidens (Wendt et al. 2015) and Schizodon intermedius Garavello and Britski, 1990 (Abdallah et al. 2016), and T. flabellum n. sp., reported in L. friderici, L. elongatus and $L$. amblyrhynchus.

Tereancistrum spp. have variable MCO shapes, with the most common being a coiled tube (with clockwise or counterclockwise rings), which is present in seven species. However, two species exhibit a different MCO pattern, either a simple tapered tube (T. kerri) or a strongly arched tube (T. arcuatus). The majority of species of Tereancistrum have counterclockwise rings (four species), while two species (T. flabellum n. sp. and T. ornatus) present clockwise rings. The vagina can be dextral or sinistral in Tereancistrum spp., while only two species (T. kerri and T. flabellum n. sp.) have a dextral vagina. Tereancistrum paranaensis needs more attention and should be revised, as in the original description the position of the vagina is dextral while the MCO presents clockwise rings (Karling et al. 2014). Two new revisions of this species were later performed, both of which confirmed that the vagina is sinistral, although one states that the rings of the MCO are counterclockwise (Wendt et al. 2015), while the other reports the opposite (Abdallah et al. 2016).

The prevalence of T. flabellum n. sp. in the Sapucaí-Mirim River was higher in L. friderici (55\%) than in L. elongatus (31.8\%) and $L$. amblyrhynchus (25\%). However, L. friderici exhibited a lower prevalence $(15.5 \%)$ in the Jurumirim Reservoir, which may be related to the number of fish specimens analyzed in each environment, which was higher in the Jurumirim
Reservoir, or due to the inherent environmental characteristics of each sample site.

Tereancistrum parvus was most prevalent $(62.5 \%)$ in $S$. nasutus, among the fish species analyzed in this study. The prevalences of this monogenean in L. friderici (12.5\%) and L. elongatus $(10 \%)$ were similar to those reported by Guidelli et al. (2011) in the floodplain of the Upper Paraná River, Brazil (3.8\% and 17.9\%, respectively).

The present study represents the first record of dactylogyrids $-T$. flabellum n. sp. and T. parvus for L. amblyrhynchus and S. nasutus, respectively. Leporinus elongatus and L. friderici were also parasitized by $T$. flabellum n. sp. and T. parvus in the Sapucaí-Mirim River, and L. friderici was parasitized by $T$. flabellum n. sp. in the Jurumirim Reservoir, in the south east of Brazil. These findings extend our knowledge of the host-parasite relationship and geographical distribution of this monogenean genus in the Neotropical region.

\section{ACKNOWLEDGMENTS}

The authors would like to thank Edmir Daniel Carvalho (in memoriam), Sandro Geraldo de Castro Britto and Diogo Freitas Souza for logistical support during the collections; Daniel Marques da Silva for assistance with the preparation of scientific drawings; and Walter Boeger for his critical reviews of this article. We are grateful to Fundação de Amparo à Pesquisa do Estado de São Paulo (FAPESP) (Process 2011/23588-8, 2011/22603-3, 2013/19776-9, 2014/14298-4 and 2015/11542-4), and Coordenação de Aperfeiçoamento de Pessoal de Nível Superior (CAPES) (AUX-PE-PNPD $3005 / 2010$ ) for financial and scientific support, and the post-graduate scholarships granted to; and Fundação de Apoio a Pesquisa, Ensino e Extensão (FUNEP) (Process 1.01852/2011), Duke Energy, Central Elétrica Anhanguera (CELAN) for financial and logistical support. R. J. da Silva is supported by Conselho Nacional de Desenvolvimento 
Científico e Tecnológico (CNPq) (307808/2014-9) and CNPq-PROTAX (440496/2015-2) / FAPESP 2016/50377-1.

\section{REFERENCES}

ABDALLAH VD, AZEVEDO RK, ALVES KGD, CAMARGO AA, VIEIRA DHMD AND SILVA RJ. 2016. The morphology of Tereancistrum paranaensis (Dactylogyridae) infecting Schizodon intermedius, with a key to the species. Neotrop Helminthol 10: 5-12.

BUSH AO, LAFFERTY KD, LOTZ JM AND SHOSTAK AW. 1997. Parasitology meets ecology on its own terms: Margolis et al. revisited. J Parasitol 83: 575-583.

CEPEDA PB, CECCARELLI PS AND LUQUE JL. 2012.

A new species of Tereancistrum (Monogenoidea, Dactylogyridae) parasitic on Prochilodus lineatus (Valenciennes, 1837) (Characiformes) from Mogiguaçu river, Brazil. Neotrop Helminthol 6: 205-210.

COHEN SC, JUSTO MC AND KOHN A. 2013. South American Monogenoidea parasites of fishes, amphibians and reptiles, Rio de Janeiro, Oficina de livros, 663 p.

COHEN SC, KOHN AAND BOEGER WA. 2012. Neotropical Monogenoidea. 57. Nine new species of Dactylogyridae (Monogenoidea) from the gill of Salminus brasiliensis (Characidae, Characiformes) from the Paraná river, State of Paraná, Brazil. Zootaxa 3049: 57-68.

GARAVELLO JC AND BRITSKI HA. 2003. Family Anostomidae. In: Reis RE, Kullander SO and Ferraris Jr CJ (Eds), Check List of the Freshwater Fishes of South and Central America, Porto Alegre: EDIPUCRS, p. 71-84. GUIDELLI G, TAVECHIO WLG, TAKEMOTO RM AND PAVANELLI GC. 2011. Relative condition factor and parasitism in anostomid fishes from the floodplain of the Upper Paraná River, Brazil. Vet Parasitol 177: 145-151.

KARLING LC, LOPES LPC, TAKEMOTO RM AND PAVANELLI GC. 2014. New species of Tereancistrum (Dactylogyridae) monogenean parasites of Schizodon borellii (Characiformes, Anostomidae) from Brazil, and emended diagnosis for T. parvus. Acta Sci Biol Sci 36: 365-369.

KRITSKY DC, THATCHER VE AND BOEGER VA. 1986. Neotropical Monogenea. Revision of Urocleidoides (Dactylogyridae, Ancyrocephalinae). Proc Helminthol Soc Wash 53: 1-37.

KRITSKY DC, THATCHER VE AND KAYTON RJ. 1980. Five new species from South America with the proposal of Tereancistrum gen. n. and Trinibaculum gen. n. (Dactylogyridae: Ancyrocephalinae). Acta Amaz 10: 411417.

LIZAMA MA, TAKEMOTO RM AND PAVANELLI GC. 2004. New species of Tereancistrum Kritsky, Thatcher and Kayton, 1980 (Monogenea: Dactylogyridae: Ancyrocephalinae) from the gills of Prochilodus lineatus (Osteichthyes: Prochilodontidae) from the upper Paraná River floodplain, Brazil. Syst Parasitol 57: 45-49.

MIZELLE JD. 1936. New species of trematodes from the gills of Illinois fishes. Am Midl Nat 17: 785-806.

NELSON JS. 2006. Fishes of the world, $4^{\text {th }}$ ed., New York: J Wiley \& Sons, $601 \mathrm{p}$.

THATCHER VE. 2006. Amazon fish parasites, $2^{\text {nd }}$ ed., Bulgaria, Pensoft, 508 p.

WENDT EW, MONTEIRO CM AND AMATO SB. 2015. New data on Tereancistrum parvus Kritsky et al. and $T$. paranaensis Karling et al. (Monogenea: Dactylogyridae) from Leporinus obtusidens Valenciennes (Characiformes: Anostomidae) from Lake Guaíba, Southern Brazil. Neotrop Helminthol 9: 203-210. 